\title{
Behavior of CD44 Receptors in Mammary Tumors of Dogs
}

\author{
Geórgia M. Magalhães ${ }^{1}$, Ana Carolina T. Silveira ${ }^{2}$, Danísio P. Munari ${ }^{1}$, Antonio C. Alessi ${ }^{1}$ \\ ${ }^{1}$ Department of Veterinary Pathology, Sao Paulo State University, Sao Paulo, Brazil \\ ${ }^{2}$ Department of Animal Science, Sergipe Federal University, Sergipe, Brazil \\ Email: georgiamode@hotmail.com
}

Received January 5, 2012; revised February 20, 2012; accepted April 5, 2012

\begin{abstract}
CD44 is a cell adhesion molecule closely related to tumor progression in humans. In canine mammary tumors, little information is available about this molecule. The aim of this study was to analyze, by immunohistochemistry, the behavior of this molecule in canine mammary tumors with or without the presence of metastasis. The dogs were divided in groups without metastasis (G1) and with metastasis (G2, with subsets A—original neoplasia and B-metastatic neoplasia). Tumors were classified according to the World Health Organization (WHO) criteria. The cells were counted whereby the plasma membrane and/or cytoplasm are stained. There was a significant increase in the number of cells immunostained for CD44 in the metastastic masses (G2B) as compared to groups G1 and G2A. It is concluded that in metastatic mass there was a significant increase in CD44 receptors, probably important for biology of the mammary tumor of dogs.
\end{abstract}

Keywords: Dogs; Oncology; Mammary Tumors

\section{Introduction}

CD44 is a multifunctional adhesion molecule that belongs to the transmembrane glycoprotein family and has a close relationship to tumor progression [1]. It is involved in cell-cell interactions and interactions between cells and the matrix [2]. There are multiple isoforms of CD44 reflecting differential roles like invasion, migration, proliferation, angiogenesis, metastasis and tumor infiltration by T lymphocytes [1]. The role of CD44 isoform v6 in human breast tumors is contradictory. Some authors have made a direct relation between tumor invasion and metastasis [3]. Other authors have reported the variant CD44v6 as a less aggressive tumor and therefore without clinical significance in breast tumors [4]. In normal breast tissues CD44v6 seem to be up-regulated during puberty and down-regulated during lactation and involution. This indicates that CD44 may be regulated in part by steroid hormones [5]. Authors [6] have showed that CD44 is expressed in primary tumors and over expressed in lymph embolus tumors and metastasis.

Mammary tumors represent approximately 52\% of all cancers in female dogs, and $50 \%$ of them are malignant [7]. In dogs, the behavior of the CD44 adhesion molecule was reported by Madrazo et al. [8], who limited its use as a marker of malignancy in canine mammary tumors. Paltian et al., [9] associates greater CD44 staining with benign tumors or with canine mammary tumors that have relatively benign behavior. No more studies were found in the literature.
The aim of this study is evaluate, by immunostaining, the comportament of CD44 receptor in malignant canine mammary neoplasias with and without metastasis in lymph node.

\section{Materials and Methods}

Twenty female dogs bearing malignant mammary tumors were divided in two groups. Group 1 consisted of 10 dogs without visible metastasis (G1). Group 2 consisted of 10 dogs with malignant mammary tumors with metastasis. From this group it was considered the primary neoplasia mass (G2A) and metastatic mass in lymph node or lymphatic vessels (G2B). Normal mammary tissues of five dogs bearing no tumors were included to provide a description only. These dogs do not enter into the statistical analysis.

Fragments of mammary tumor and draining lymph node were acquired from the Veterinary Hospital, FCAVUNESP, Jaboticabal, SP and from private clinics. Samples were collected from females that were submitted to mastectomy with no predilection for breed or age. There was no bias towards mammary location, but inguinal breasts and inguinal lymph nodes were the most prevalence. The study was approved by the FCAV-UNESP Ethics and Scientific Committee (protocol number: 025600-08).

The neoplasia classification and the degree of malignancy were classified by light microscopy analysis according to the World Health Organization criteria [10]. 
The streptavidin peroxidase complex (ABC) immunohistochemical technique was performed, as developed by Hsu et al., [11] with little modification. The blocking of endogenous peroxidase was performed with $5 \%$ of hydrogen peroxide in methanol. Antigen retrieval was performed with citrate buffer, $\mathrm{pH} 6$ in microwave oven for 10 minutes, in which the first 2 min were carried out at maximum power and the remaining time at the warm temperature setting. The nonspecific protein was blocked with the commercial product (Protein Block, DAKO, cat. X0909). The CD44v6 monoclonal antibody (clone DF1485, DAKO) was used at a 1:50 dilution (Antibody Diluent, DAKO, Code S0809) with incubation at $4^{\circ} \mathrm{C}$ for $18 \mathrm{~h}$. As a secondary byotinylated antibody was used DAKO LSAB kit, ref K0690. The slides were revealed by chromogenic substrate diaminobenzidine (Dab-DAKO, ref. K3466) and counterstained with Harris Hematoxylin. Normal mammary glands that were located surrounding the neoplasia were used as interne positive controls, and Dako diluent without primary antibody was used as the negative control. Staining was considered positive when the plasma membrane and/or the cytoplasm were brown stained. To quantify the staining frequency, 4 fields per section were randomly selected, and a total of 100 cells per field were counted including stained and non-stained cells using a $40 \times$ objective lens.

Percent counts were performed in G1, G2A and G2B. The T-test was used to compare results. Statistical analyses were completed using the SAS computer program (SAS 9.1, SAS Institute, Cary, NC, USA).

\section{Results}

The histological type, degree of malignancy, age, breed, ovarian salpingo-hysterectomy and the survival time are presented in Tables 1 and 2. Only one dog (G1) was spayed before mastectomy surgery.

In the dogs with normal mammary glands, all five dogs presented $100 \%$ epithelial glands cells stained positive for CD44. These results do not participate in the statistical analyses and are provided for description only. No stained cells was present in negative controls, in all groups.

Table 1. Results of histological type, degree of malignancy, age, breed and the survival time in dogs bearing malignant mammary tumors without metastasis (G1).

\begin{tabular}{|c|c|c|c|c|c|}
\hline Dog & Histological Type & Degree of Malignancy & Age (years) & Breed & Survival Time (months) \\
\hline 1 & $\mathrm{SC}^{\mathrm{a}}$ & II & 8 & German shepherd & over 36 \\
\hline 2 & $\mathrm{CC}$ & II & 9 & Teckel & over 24 \\
\hline 3 & SC & III & 9 & Mixed breed & Not informed \\
\hline 4 & CC & II & 11 & Cocker Spaniel & over 19 \\
\hline 5 & SCTP & III & 6 & Mixed breed & 18 \\
\hline 6 & SCTP & III & 8 & German shepherd & 1 \\
\hline 7 & CC & II & 15 & Mixed breed & over 12 \\
\hline 8 & $\mathrm{CC}$ & I & 6 & Boxer & over 14 \\
\hline 9 & SCTP & I & 8 & Poodle & over 12 \\
\hline 10 & $\mathrm{CC}$ & I & 10 & Poodle & over 12 \\
\hline
\end{tabular}

${ }^{\mathrm{a}} \mathrm{SC}$ : simple carcinoma solid pattern, CC: complex carcinoma, SCTP: simple carcinoma tubulopapillary pattern.

Table 2. Results of histological type, degree of malignancy, age, breed and the survival time in dogs bearing malignant mammary tumors with metastasis (G2 A and B).

\begin{tabular}{|c|c|c|c|c|c|}
\hline Dog & Histological Type & Degree of Malignancy & Age (years) & Breed & Survival Time (months) \\
\hline 11 & SCTP & II & 11 & Mixed breed & $0^{\mathrm{b}}$ \\
\hline 12 & $\mathrm{SC}^{\mathrm{a}}$ & II & 11 & Teckel & 4 \\
\hline 14 & SCTP & II & 12 & Mixed breed & over 19 \\
\hline 15 & SCTP & II & 13 & Teckel & Not informed \\
\hline 16 & SCTP & II & 13 & Mixed breed & 0 \\
\hline 18 & SCTP & II & 9 & Teckel & 14 \\
\hline 19 & SCTP & II & 9 & Boxer & 1 \\
\hline 20 & SC & III & 12 & Teckel & 0 \\
\hline
\end{tabular}

${ }^{\mathrm{a}} \mathrm{SC}$ : simple carcinoma solid pattern, CC: complex carcinoma, SCTP: simple carcinoma tubulopapillary pattern; ${ }^{\mathrm{b}}$ Time 0 means that the female dog died during surgery. 
There was no significant difference between G1 and G2A (Tables 3 and 4). On the other hand, the percentage number of marked cells in group G2B were significant higher ( $<$ 0.05) in relation to G1 and G2A (Tables 3 and 4). In simple tubulopapillary carcinomas, more staining was observed in the tubules closer to the normal cells and in the external cell layers in the papilla (Figure 1). Two of four solid carcinomas exhibited little staining in the primary tumor. Neoplastic cells in the lymphatic vessels were, for the most part, grouped and stained. In the lymph nodes, the stained cells were predominantly grouped in the subcapsular sinus. In only two cases cells invaded the lymph nodes through the lymphatic cords and had reached the medullary region.

Table 3. Percent of CD44 immunostained cells in malignant mammary neoplasia without metastasis (G1).

\begin{tabular}{cc}
\hline Dog & Malignant without metastasis (G1) \\
\hline 1 & 42 \\
2 & 23 \\
3 & 28 \\
4 & 27 \\
5 & 25 \\
6 & 41 \\
7 & 65 \\
8 & 64 \\
9 & 47 \\
10 & 51 \\
Median & $41.30 \pm 14.82^{\mathrm{a}}$ \\
\hline
\end{tabular}

Table 4. Percent of CD44 immunostained cells in malignant mammary neoplasia with metastasis (G2 A and B).

\begin{tabular}{ccc}
\hline Dog & $\begin{array}{c}\text { Primary neoplasia } \\
\text { mass (G2 A) }\end{array}$ & $\begin{array}{c}\text { Metastatic mass in lymph node } \\
\text { or lymphatic vessels (G2 B) }\end{array}$ \\
\hline 11 & 45 & 67 \\
12 & 15 & 90 \\
13 & 47 & 58 \\
14 & 42 & 69 \\
15 & 49 & 84 \\
16 & 48 & 57 \\
17 & 10 & 62 \\
18 & 64 & 83 \\
19 & 52 & 72 \\
20 & 60 & 95 \\
Median & $43.2 \pm 17.5$ & $73.70 \pm 13.50^{*}$ \\
\hline${ }^{*}<0.05 \%$ & &
\end{tabular}

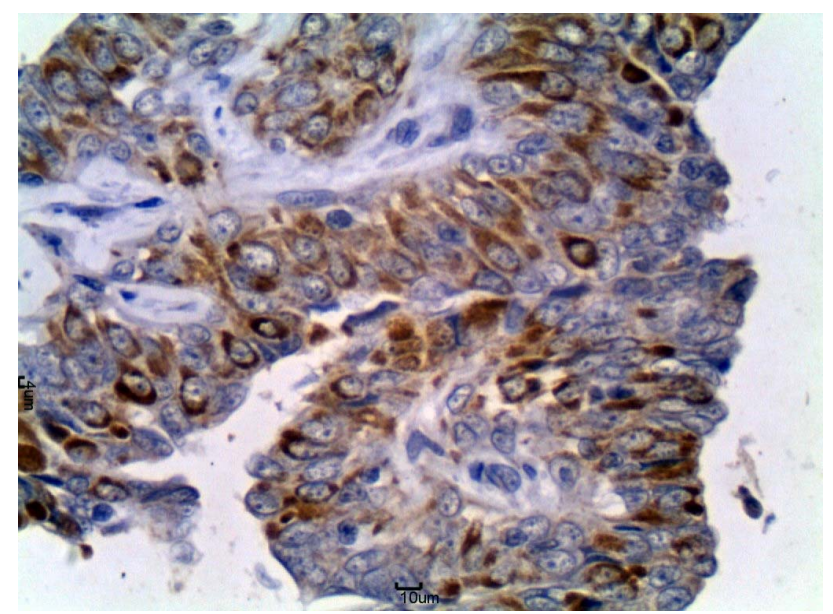

Figure 1. Tubulopapillary carcinoma of female dog, group G2 A. Immunohistochemical staining for CD44 in neoplastic epithelial cells (arrows). DAB chromogen and Harris Hematoxylin counterstain. $\mathrm{Obj} .40 \times$.

\section{Discussion}

Studies have shown that the histological grade tends to be the most objective prognostic indicator of malignancy [12]. In this study, complex carcinomas were predominant in tumors that did not cause metastasis, while the simple classification of carcinoma was present in all metastatic tumors in the G2. These results corroborate with some authors [13] who reported that the complex tumors are rarely invasive and carcinomas tend to be simple locally invasive, and also invasive of the lymphatic vessels.

In mammary glands, CD44v6 exhibits strong immunoreactivity in normal myoepithelium and in duct epithetlial cells [4]. In our normal mammary tissue, all epithelial cells were marked by CD44. Paltian et al. [9] reported that in dogs the CD44 was expressed in normal and hyperplastic mammary tissue predominantly by ductal and alveolar epithelial cells and to a minor extent by myoepithelial cells.

In this research primary neoplasia demonstrated lower CD44 staining in relation to metastasis. In contrast with our findings, Paltian et al. [9] found in locally invasive, intravascular embolized and nodal metastatic tumour cells a moderate, homogeneous expression of CD44 a long the cellular membrane. Pozdnyakova et al. [14] found greater CD44v6 staining in primary breast tumors than in cutaneous metastases in humans. Despite using the same antibody clone, the metastasis was analyzed in the skin, while the present study analyzed lymph node metastasis. Several studies in humans have proposed that CD44 might be a prognostic biomarker to metastasis [15].

Interestingly, we observed that the CD44 adhesion molecule stained on high average (73.7\%) corroborated with Madrazo et al. [8] that found a significant reduction 
in CD44 expression in carcinomas exhibiting vascular invasion of tumor cells at the metastasis, indicating that the neoplastic cells need adhesion to withstand the new microenvironment which they are colonizing. The strong staining of cells inside the lymph vessels means that CD44 confers stability to the tumor embolus structure. This higher immunostaining in metastatic emboli increases their adhesion to endothelial cells, facilitating trans-endothelial migration [16].

\section{Conclusion}

It is concluded that there was a higher number of cells positive for CD44 receptor in metastatic neoplastic masses than in primary tumors which developed metastasis and malignant neoplasia without metastasis. This fact is probably important for the metastatic process in mammary tumors of dogs.

\section{Acknowledgements}

This research was supported by Fundação de Apoio à Pesquisa do Estado de São Paulo (FAPESP). Our thanks to the laboratory technicians Francisca A. Ardisson and Maria Inês Y. de Campos for the excellent slides.

\section{REFERENCES}

[1] M. Gotte and G. W. Yip, "Heparanase, Hyaluronan, and CD44 in Cancers: A Breast Carcinoma Perspective,” Cancer Research, Vol. 66, No. 21, 2006, pp. 1023310237. doi:10.1158/0008-5472.CAN-06-1464

[2] D. Naor, R. V. Sionov and D. Ish-shalom, “CD44: Structure, Function, and Association with the Malignant Process," Advances in Cancer Research, Vol. 71, 1997, pp. 241-319. doi:10.1016/S0065-230X(08)60101-3

[3] S. B. Wallach-Dayan, A. M. Rubinstein, C. Hand, R. Breuer and D. Naor, "DNA Vaccination with CD44 Variant Isoform Reduces Mammary Tumor Local Growth and Lung Metastasis,” Molecular Cancer Therapeutics, Vol. 7, 2008, pp. 1615-1623. doi:10.1158/1535-7163.MCT-07-2383

[4] K. Friedrichs, F. Franke, B. W. Lisboa, G. Kügler, I. Gille, H. J. Terpe, F. Hölzel, H. Maass and U. Günthert, “CD44 Isoforms Correlate with Cellular Differentiation but not with prognosis in Human Breast Cancer," Cancer Research, Vol. 55, 1995, pp. 5424-5433.

[5] L. Hebbard, A. Steffen, V. Zawadzki, C. Fieber, N. Howells, J. Moll, H. Ponta, M. Hofmann and J. Sleeman, "CD44 Expression and Regulation during Mammary Gland Development and Function,” Journal of Cell Science, Vol. 113, 2000, pp. 2619-2630.

[6] J. C. Harrell, W. W. Dye, D. C. Allred, P. Jedlicka, N. S. Spoelstra, C. A. Sartorius and K. B. Horwitz, "Estrogen
Receptor Positive Breast Cancer Metastasis: Altered Hormonal Sensitivity and Tumor Aggressiveness in Lymphatic Vessels and Lymph Nodes,” Cancer Research, Vol. 66, No. 18, 2006.

[7] G. R Rutteman, S. J. Withrow and E. G Macewen, "Tumors of the Mammary Gland,” In: S. J. Withrow and E. G. Macewen, Eds., Small Animal Clinical Oncology, 3rd Edition, W. B. Saunders, Philadelphia, 2001, pp. 455-477.

[8] J. Madrazo, R. A. Garcia-Fernandez, M. J. Garcia-Iglesias, A. J Duran, J. Espinosa and C. Perez-Martinez, "The Role of CD44 Adhesion Factor in Canine Mammary Carcinomas,” The Veterinary Journal, Vol. 180, No. 3, 2009, pp. 371-376. doi:10.1016/j.tvjl.2008.01.007

[9] V. Paltian, S. Alldinger, W. Baumgartner and P. Wohlsein, "Expression of CD44 in Canine Mammary Tumours," Journal of Comparative Pathology, Vol. 141, No. 4, 2009, pp. 237-247. doi:10.1016/j.jcpa.2009.05.007

[10] H. Misdorp, R. Else and E. Hellman, "Histologic Classification of Mammary Tumors of the Dog and Cat,” In: World Health Organization International Histological Classification of Tumors of Domestic Animals, Series 2, Vol. 7, No. 2, Armed Forces Institute of Pathology, Washington DC, 1999.

[11] S. M. Hsu, L. Raine and H. A. Fanger, "A Comparative study of Peroxidase-Antiperoxidase Method and an Avidin Biotin Complex Method for Studying Polypeptide Hormones with Radioimmunuoassay Antibodies,” American Journal of Clinical Pathology, Vol. 75, 1981, pp. 734-738.

[12] C. W. Elston and I. O. Ellis, "Pathological Prognostic Factors in Breast Cancer, I. The Value of Histological Grade in Breast Cancer: Experience from Large Study with Long Term Follow-Up,” Histopathology, Vol. 19, No. 5, 1991, pp. 403-410. doi:10.1111/j.1365-2559.1991.tb00229.x

[13] J. F. Hampe and W. Misdorp, "Tumours and Dysplasias of the Mammary Gland,” Bulletim of World Health Organization. Vol. 50, 1974, pp. 111-133.

[14] O. Pozdnyakova, M. M. Hoang, K. A. Dresser and M. Mahalingam, "Prognostic Value of E-cadherin, Beta-catenin, CD44v6, and HER2/neu in Metastatic Cutaneous Adenocarcinoma," Archives of Pathology and Laboratory Medicine, Vol. 133, No. 8, 2009, pp. 1285-1290.

[15] Y. Xin, A. Grace, M. M. Gallagher, B. T. Curran, M. B. Leader and E. W. Kay, "CD44V6 in Gastric Carcinoma: A Marker of Tumor Progression,” Applied Immunohistochemistry Molecular Morphology, Vol. 9, No. 2, 2001, pp. 138-142. doi:10.1097/00022744-200106000-00006

[16] S. Mine, T. Fujisaki, C. Kawahara, T.Tabata, T. Iida, M. Yasuda, T. Moneda and Y. Tanaka, "Hepatocyte Growth Factor Enhances Adhesion of Breast Cancer Cells to Endothelial Cells in Vitro through Up-Regulation of CD44," Experimental Cell Research, Vol. 288, No. 1, 2003, pp. 189-197. doi:10.1016/S0014-4827(03)00184-8 